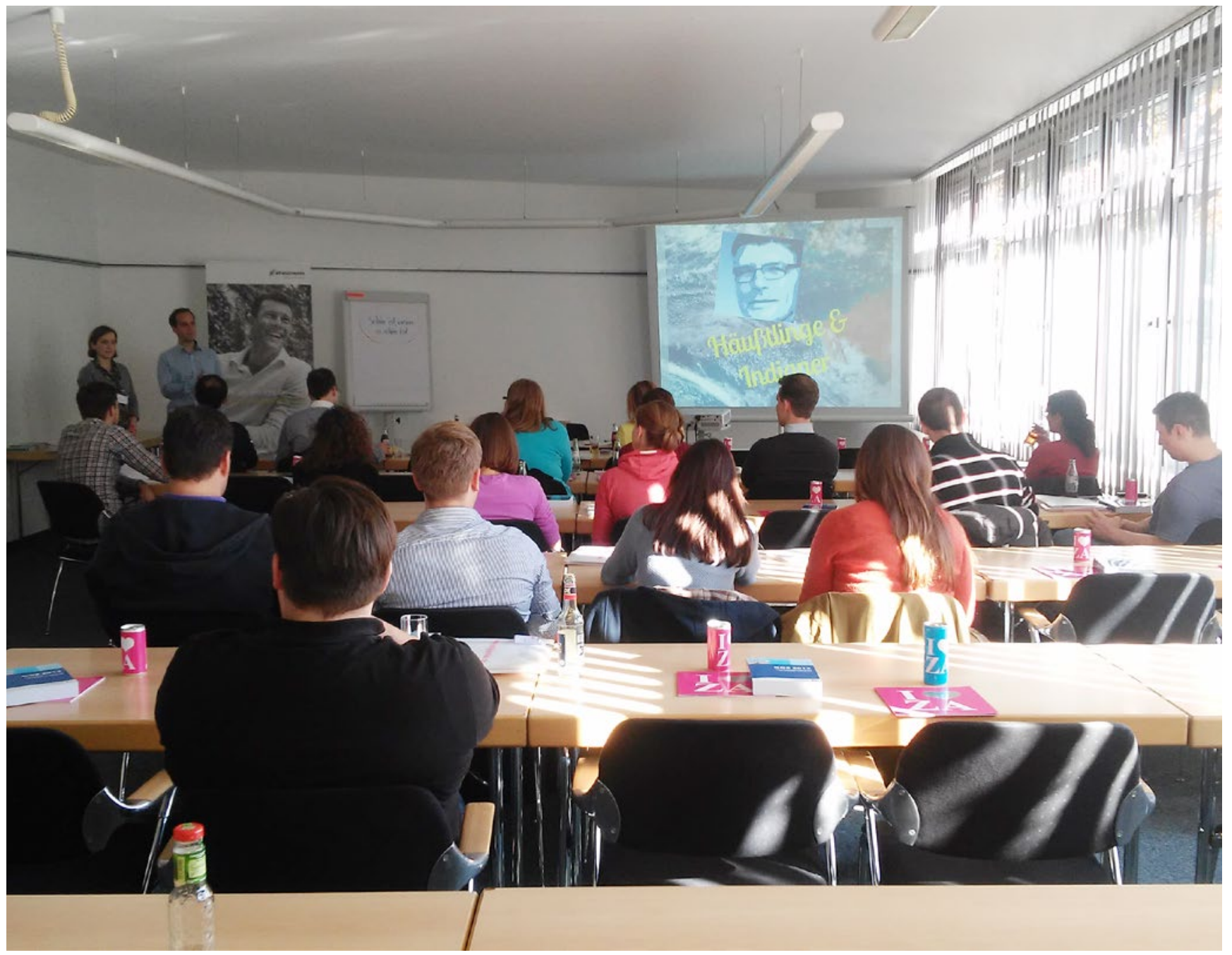

\title{
Von Häuptlingen und Implantaten
}

Super Atmosphäre, tolle Vorträge und jede Menge Spaß. So lässt sich das „young dentists meeting" in Bonn zusammefassen.

Ende Oktober trafen sich wieder junge Zahnärztinnen und Zahnärzte im Stresemann-Institut in Bonn, um auf ein Leben in der eigenen Praxis vorbereitet zu werden. Traditionell steht der Freitagnachmittag unter dem Vorzeichen Praxisführung und Betriebswirtschaft, und der Samstag ist dem zahnmedizinischen Fachvortrag gewidmet.

Dipl.-Päd. Herbert Prange vermittelte in seinem interaktiven Vortrag „Häuptlinge und Indianer - Praxisführung konkret“, wie Berufseinsteiger Denk- und Handlungsweisen zu strategisch und lösungsorientierten Überlegungen hinführen können, um einerseits ein gutes Praxisteam zu bilden, aber auch dem Patienten gegenüber souverän aufzutreten. Prange nannte zahlreiche praktische Beispiele, oft gepaart mit einer guten Portion Humor. Beim gemeinsamen Abendessen konnten sich die Teilnehmer in ge- selliger Runde austauschen. Auch der Referent stand für weitere Fachfragen zur Verfügung.

„Implantatchirurgie Step-by-Step mit praktischen Übungen am Kunststoffkiefer" lautete das Thema von PD Dr. Dr. Markus O. Klein. In seinem Vortrag zum Status quo der Implantologie stellte Klein Indikationen für eine Implantation auch bei erschwerten Bedingungen vor, zeigte welche Verfahren derzeit genutzt werden (zum Beispiel Bonesplit, Osteodistraktraktion, Interpositionsosteoplasik) und welche Implantattypen und Materialien zum Einsatz kommen. Zum Schluss stand noch ein praktischer Teil auf dem Programm. Die young dentists konnten unter fachkundlicher Anleitung die Sofortversorgung auf angulierten wurzelförmigen Implantaten ausprobieren.

Dr. Christian Honert 